\title{
FORMAR-SE PARA ENSINAR: experiência de um Instituto Federal
}

\author{
M. R. S. L. RODRIGUES* e M. C. S. FREITAS \\ *Email: marcela.rodrigues@ifms.edu.br \\ Instituto Federal de Educação, Ciência e Tecnologia de Mato Grosso do Sul
}

Artigo submetido em junho/2016 e aceito em novembro/2016

DOI: $10.15628 /$ rbept.2016.4679

\section{RESUMO}

Este artigo compreende parte de trabalho de pesquisa de Mestrado Profissional em Educação na Área de Políticas Públicas e Gestão da Educação Profissional e Tecnológica do Programa de Pós-Graduação em Educação da Faculdade de Educação da Universidade de Brasília e teve como objetivo geral analisar a contribuição do Curso de Especialização em Docência para Educação Profissional, Científica e Tecnológica para a prática pedagógica dos docentes não licenciados do IFMS campus Coxim justificado pela necessidade e importância da formação pedagógica para ensinar. Os resultados do estudo revelaram que os saberes docentes dos professores não licenciados são fundamentados nas experiências acadêmicas e pessoais vivenciadas e que vão se solidificando e direcionando a prática docente por meio de formação continuada, pedagógica e/ou específica, a fim de constante atualização, acompanhamento do meio tecnológico e melhor formação do estudante. Todavia, evidenciou-se nos relatos que a formação pedagógica, ofertada por meio do curso de Especialização, contribuiu para construção do saber docente, especificamente pedagógica, dos professores não licenciados do IFMS campus Coxim, porém sem o caráter de terminalidade, sendo necessário, para tanto, oferta de programa de formação continuada e permanente para todos os professores, licenciados ou não, direcionada a construção do saber docente e coletivo para a Educação Profissional e Tecnológica (EPT).

PALAVRAS-CHAVE: Formação de Professores para EPT, Formação Pedagógica, Saber Docente, Trabalho Docente, Educação Profissional.

\section{FORM TO TEACH: experience of a Federal Institute}

\begin{abstract}
This article comprises of Professional Master's research work in education in the area of Public Policy and Professional Education Management and Technology at the Graduate Program in Education of the Faculty of Education at the University of Brasilia and aimed to analyze the contribution of Specialization course in teaching for Professional Education, Science and Technology for teaching practice of teachers not licensed IFMS cushion campus justified by the need and importance of pedagogical training for teaching. The study results revealed that the knowledge teachers of unlicensed teachers are based on academic and personal experiences and that will solidify and directing the
\end{abstract}

teaching practice through continuing education, teaching and / or specific, in order to constantly update, monitoring of technological environment and better training of the student. However, it was evidenced in reports that pedagogical training, offered through the specialization course, contributed to the construction of teaching knowledge, specifically educational, nonlicensed teachers IFMS campus Coxim, but without the character of terminally, being required, to do, so provision of continuous and permanent training program for all teachers, graduates or not, directed the construction of teaching knowledge and collective for Vocational Education and Training (VET).

KEYWORDS: Teacher Training for VET, Pedagogical Training, Teaching Knowledge, Teaching Work, Vocational Education and Training. 


\section{INTRODUÇÃO}

Este estudo se constitui na tentativa de contextualizar os fatores de construção do saberes docentes pelos professores não licenciados que participaram do Curso de Especialização em Docência para Educação Profissional, Científica e Tecnológica, como formação pedagógica, que visa proporcionar ao professor o desenvolvimento de saber docente que rompa com a dualidade entre a formação clássica e a formação para o trabalho e, ainda, objetiva a formação de sujeitos autônomos, emancipados e fundamentados no enriquecimento científico, cultural, político e profissional.

Além das exigências legais, a formação pedagógica para atuar na EPT destina-se a suprir as demandas observadas nas pesquisas em educação e no contexto educacional, como a melhor compreensão sobre os processos de ensino e aprendizagem, as especificidades da organização escolar e o papel do professor no cenário da educação profissional, reiteradas pelas interações entre educação e o mundo do trabalho. Desta forma, é ímpar que o docente se apodere de suas competências e que esteja mais afinado com as mudanças sociais e tecnológicas, para tanto é preciso qualificar-se e formar-se, continuadamente.

Dessa forma, o texto é composto de duas partes seguidas das considerações finais. $\mathrm{Na}$ primeira parte, procurou-se discutir sobre as concepções de trabalho e saber docente. Na segunda, apresenta-se e analisam-se os dados resultantes da pesquisa que foram categorizados em: Desenvolvimento docente - apresenta o desenvolvimento profissional dos sujeitos; Docência para os sujeitos - aborda os entendimentos dos sujeitos acerca do que é docência; Experiência docente - relata as primeiras impressões dos sujeitos como docentes; Construção dos saberes docentes traz as fontes utilizadas para a construção do saber docente; Formação Docente - evidencia a percepção dos sujeitos a respeito da formação pedagógica para a docência. A discussão é finalizada com os apontamentos finais sobre a pesquisa realizada.

\section{FORMAÇÃO DOCENTE NA EPT}

\subsection{Trabalho Docente}

A docência constitui o trabalho do professor, fortemente contextualizado, concreto e posicionado, que não se restringe aos processos de ensino e aprendizagem, mas também aos "aspectos da gestão do ensino, da organização escolar e das relações da escola com seu entorno", segundo Krahe et al (2012, p.2)

Leite, Ghedin e Almeida (2008, p. 99) corroboram com o conceito de profissionalidade docente,

entendida como processo de construção/reconstrução das respostas práticas (saberes profissionais) dos docentes frente às questões que se apresentam na sala de aula, na escola, na relação com os demais profissionais, com os pais, com a 
sociedade, enfim, e que se traduz na re-configuração do modo de ser professor e estar na profissão.

O trabalho docente é o constituído de conjuntos de comportamentos, conhecimentos e valores que Sacristán apud Leite, Ghedin e Almeida (2008, p. 113) ratifica como

conjunto de aspectos relacionados diretamente ao modo como os professores desempenham seu trabalho que, logicamente, pressupõe os múltiplos conhecimentos capazes de dar sustentação às ações que eles desenvolvem.

A docência está em constante transformação e esse caráter inconcluso do trabalho docente e, consequentemente, do saber docente, oportuniza aos professores contínuos questionamentos sobre suas próprias ações articuladas em estreita relação entre professor, escola, alunos e demais profissionais.

Referendando Tardif e Lessard (2013, p. 35), o trabalho docente é interativo, reflexivo, imaterial e sobre o outro, uma vez que é interdependente das relações e interações sociais. "A docência é um trabalho cujo objeto não é constituído de matéria inerte ou de símbolos, mas de relações humanas com pessoas capazes de iniciativa e dotadas de uma certa capacidade de resistir e participar da ação dos professores".

Ainda segundo os autores Leite, Ghedin e Almeida (ibidem, p.120) o trabalho docente tem um conjunto de conhecimentos (saberes) teóricos e práticos que o sustentam que são reelaborados continuamente "ao longo de toda a vida profissional, por meio de situações formativas formalmente organizadas (como os cursos), ou vividas cotidianamente no trabalho, ou nos momentos em se planeja, avalia, reflete, discute o próprio trabalho".

\subsection{Saberes Docentes}

Mas o que são os saberes docentes?

Nunes (2001, p. 29) utiliza-se de Fiorentini et al (1998) para apresentar a evolução da valorização dos saberes docentes: a década de 1960 foi caracterizada, quase que exclusivamente pelos saberes específicos, 1970, por meio dos aspectos didáticos-metodológicos e domínio de conteúdos, 1980, dominados pela dimensão política e ideológica da prática pedagógica e nos anos de 1990, marcados por novos enfoques e paradigmas para compreensão da prática docente e dos saberes dos professores.

Para Gauthier et al (1998 apud NUNES, 2001, p.34) "os saberes docentes são aqueles adquiridos para o ou no trabalho e mobilizados, tendo em vista uma tarefa ligada ao ensino e o universo de trabalho do professor, exigindo da atividade docente uma reflexão prática".

Os saberes necessários à prática docente "incluem tanto as questões relacionadas aos conhecimentos e competências, quanto àquelas referentes às habilidades e atitudes dos professores" (AGUIAR e FERREIRA, 2007, p.74), que se constrói através da relação teoria-prática, entre os conhecimentos adquiridos ao longo da trajetória pessoal, profissional e acadêmica. As autoras ainda contribuem compreendendo que os saberes teóricos se articulam com os saberes da prática, ressignificando-os e sendo por eles ressignificados continuamente. A partir daí, 
podemos afirmar que a teoria tem o importante papel de subsidiar a análise dos diferentes aspectos do ato educativo, favorecendo o desenvolvimento da profissionalidade docente.

Estudiosos em formação docente são enfáticos em pontuar que o saber docente é construído pelo professor, que consciente de sua ação em sua própria formação, e por meio da perspectiva crítico-reflexiva, forma-se. Corrobora Nóvoa (1991, p.13), "a formação não se constrói por acumulação (de cursos, de conhecimentos ou de técnicas), mas sim através de um trabalho de reflexividade crítica sobre as práticas e de (re) construção permanente de uma identidade pessoal".

Pimenta (2012, p.21) identifica três tipos de saberes da docência: saberes da experiência, vivenciados; saberes do conhecimento, específicos; saberes pedagógicos, construídos a partir das necessidades pedagógicas reais. No entanto, enfatiza a necessidade de superação dessa fragmentação dos saberes para a uma re-significação da formação dos professores.

Tardif apresenta o saber docente, como um saber plural e originário: de saberes da formação profissional, das ciências da educação e da ideologia pedagógica, e pedagógicos; de saberes disciplinares, transmitidos pelos cursos universitários; de saberes curriculares, programas escolares; de saberes experienciais, saberes emergentes do trabalho cotidiano e no conhecimento de seu meio. E ainda complementa com "o professor ideal é alguém que deve conhecer sua matéria, sua disciplina e seu programa, além de possuir certos conhecimentos relativos às ciências da educação à pedagogia e desenvolver um saber prático baseado em sua experiência cotidiana com os alunos". (TARDIF, 2006, p. 39)

Os saberes docentes são por Tardif, ainda complementados como: temporais, adquiridos através do tempo; plurais e heterogêneos, porque se utilizam de muitas teorias, concepções e técnicas, conforme a necessidade; personalizados e situados, associados aos sujeitos, experiências e situação de trabalho, para as negociações do trabalho coletivo.

Esteve (2006 apud LÜDKE e BOING, 2007, p. 1.192) propõe objetivos importantes para a formação do futuro professor: elaborar a própria identidade, dominar as técnicas básicas de comunicação e interação na aula; organizar o trabalho em classe e adaptar os conteúdos aos estudantes.

É (quase) unânime junto aos estudiosos de formação docente que o saber docente é essencialmente ligado à prática reflexiva do professor e a relação que este faz entre teoria e prática.

Corroborado pelo movimento sugerido por Schön, apontado por Dorigon e Romanwski $(2008$, p. 7)

Para ele, então, há a reflexão na ação, a reflexão sobre a ação e a reflexão sobre a reflexão na ação, sendo que as duas primeiras são separadas apenas pelo momento que acontecem: a primeira ocorre durante a prática e a segunda depois do acontecimento da prática, ou seja, quando a ação é revista e analisada fora do contexto. É nessa reflexão sobre a ação que tomamos consciência do conhecimento tácito e reformulamos o pensamento na ação tentando analisá-la, percebendo que é um ato natural. A terceira, ou seja, a reflexão sobre a reflexão na ação é aquela que ajuda o profissional a desenvolver-se e construir sua forma 
pessoal de conhecer. Trata-se de olhar retrospectivamente a ação, refletir sobre o momento da reflexão na ação, ou seja, o que aconteceu, o que se observou, qual o significado atribuído e que outros significados podemos atribuir ao que aconteceu. (grifo nosso)

Sem desconsiderar o saber docente como resultante das relações históricas e sociais e do contexto no qual está inserido, como diz Nóvoa (1991, p.13) “Os momentos de balanço retrospectivo sobre os percursos pessoais e profissionais são momentos em que cada um produz 'sua' vida, o que no caso dos professores é também produzir a 'sua' profissão."

Há que se destacar os saberes que constituem a base profissional dos professores da EPT, considerando que nesta modalidade de ensino, como apontam Gariglio e Burnier, a docência

é exercida por pessoas que foram formadas em outras áreas, em geral técnicas, distantes do campo da educação e que, raras vezes, tiveram acesso a algum tipo de formação pedagógica anterior ao exercício da docência. Além disso, essas pessoas muitas vezes possuem experiências profissionais nas áreas técnicas que constituem sua visão de mundo e de profissional da área, o que impactará sua atuação na formação dos alunos. (GARIGLIO e BURNIER, 2012, p. 219).

Em estudos realizados por esses autores, com professores do ensino técnico das redes federal, estadual e particular de diferentes estados, foi apontada a necessidade e a ansiedade dos mesmos no que se refere aos saberes pedagógicos, como:

teorias do conhecimento, epistemologia e história da ciência e da técnica, desenvolvimento da criatividade, ensino por projetos, a questão da motivação do jovem, a contextualização do ensino, a montagem de currículos, o estudo das políticas educacionais e a relação das políticas de Ensino Profissional com o contexto geral. Além disso, os docentes da EP das escolas públicas ainda demandam os saberes que os capacitem a preparar aulas, acompanhar as turmas, preparar recursos didáticos, executar as atividades anteriores e posteriores às aulas, a planejar, desenvolver e avaliar trabalhos interdisciplinares, a controlar a atividade dos alunos e assegurar a disciplina em sala de aula e a ter desenvoltura na comunicação oral. (ibidem, p. 223).

No mesmo estudo, observou-se que os "saberes oriundos da produção, da empresa, do mercado são profundamente valorizados pelos professores" da EPT, que os consideram de grande utilidade para as aulas dos cursos técnicos; "para atualização tecnológica e para inclusão, nos cursos, de questões relativas à dinâmica do cotidiano do trabalho, à organização cotidiana da produção, às relações sociais de produção e ao conjunto de saberes e habilidades correlatas a tais questões." (ibidem, p. 224).

No entanto, como o "ofício docente na EP é um ofício feito de saberes" e com grande ênfase nos saberes técnico, tecnológico e do mercado/produção, enfim no saber-fazer, "os saberes pedagógicos ocupam uma posição de menor status na hierarquia dos saberes necessários a ensinar" (ibidem, p.229-30). Daí a importância de enfatizar a valorização do saber pedagógico que se dá por meio da formação de professores para a Educação Profissional, Científica e Tecnológica, com vistas a combater a percepção do senso comum que aponta para: "A academia está longe de mim". O que é assegurado por Imbernón (2011, p. 63) "dotar o futuro professor ou professora de 
uma bagagem sólida nos âmbitos científico, cultural, contextual, psicopedagógico e pessoal deve capacitá-lo a assumir a tarefa educativa em toda a sua complexidade".

Corroboram Dias e Aranha (2007, p. 48) "os docentes são sujeitos de saber e de conhecimento e, portanto, gestores de si no trabalho".

As contribuições dos autores nos levam a concluir que ensinar é mobilizar uma variedade de saberes compostos, com destaque aos experienciais, para reinventá-los, adaptá-los e transformá-los no trabalho docente.

\subsection{Formação Docente}

Ao longo da história da EPT e por meio da legislação que a regulamenta, conforme justifica Machado (2008, p.3) observa-se "a falta de concepções teóricas consistentes e de políticas públicas amplas e contínuas tem caracterizado, historicamente, as iniciativas de formação docentes especificamente para a educação profissional, no Brasil."

A mesma autora advoga a favor de licenciaturas para a educação profissional a fim de atender à carência de docentes qualificados para a EPT considerando a expansão desta modalidade de ensino, aliado ao entendimento de que esta contempla:

processos educativos e investigativos de geração e adaptação de soluções técnicas e tecnológicas de fundamental importância para o desenvolvimento nacional e o atendimento de demandas sociais e regionais, o que requer $o$ provimento de quadros de formadores com padrões de qualificação adequados à atual complexidade do mundo do trabalho. (MACHADO, 2008, p. 7).

E ainda, por considerar que com as licenciaturas oportunizam espaço

para o desenvolvimento de pedagogias apropriadas às especificidades da educação profissional, o intercâmbio de experiências no campo da educação profissional, o desenvolvimento da reflexão pedagógica sobre a prática docente nesta área, o fortalecimento do elo entre ensino-pesquisa-extensão, pensar a profissão, as relações de trabalho e de poder nas instituições escolares, a responsabilidade dos professores etc. (MACHADO, 2008, p. 8).

A licenciatura como formação para docentes da EPT, também proposta por Pereira (2004, p.3) visa a "preparar um professor afinado com práticas pedagógicas voltadas para a construção do conhecimento de acordo com as exigências que se colocam no atual estágio do desenvolvimento da humanidade" que trabalhe de forma integrada e articulada, tenha domínio dos conteúdos para a realização da "transposição didática contextualizada e integrada às atividades práticas e de pesquisa".

Prossegue o autor afirmando que

para a formação do professor em EPT deve ser estabelecido o entrecruzamento do conteúdo específico de uma determinada área da formação profissional [...] com aqueles destinados ao domínio do que é específico à produção do conhecimento. Ao que se incorporam uma dimensão formativa sócio-político- 
cultural (imprescindível à formação de todo cidadão) e a dimensão pedagógica. (PEREIRA, 2004, p. 7).

Diante disso é inegável que a formação pedagógica do docente da EPT deve se referendar nas exigências do mundo do trabalho, no avanço das tecnologias, nos aspectos legais, na articulação entre os conteúdos gerais e específicos e na formação integral dos estudantes.

Fundamentada em estudos de Oliveira, Nóvoa, Perrenoud, Burnier, Passos e Novicki acreditam que

[...] uma política de formação de docentes para a EP deve implantar programas permanentes de formação continuada, que terão como foco necessidade explicitadas por professores, como, por exemplo, mercado de trabalho, cotidiano escolar, participação institucional democrática, preparação para saber lidar com os jovens, além de uma sólida atualização que possa envolver teoria, técnica e prática direcionadas ao exercício da docência, de maneira a fundamentar e orientar projeto e atividades escolares. (PASSOS e NOVICKI, 2013, p. 5).

Os estudos de Gomes (2004, p. 8) com professores da EPT apontam que os mesmos precisam aliar conhecimento teórico ao conhecimento prático, transformando ideias em ações, precisam formar profissionais capazes de gerenciar sua vida e carreira, além de estarem abertos "à uma necessidade de formação permanente e de uma reciclagem profissional em atendimentos às demandas do mundo do trabalho" (sic), que não se esgota em procedimentos lineares e técnicos, mas passa necessariamente por um processo de educação inicial e continuada, que tem como concepção a aquisição das autonomias intelectual, social e humana adquiridas por meio do aceso aos conhecimentos científico, tecnológico e sócio-histórico.

Moura (2008, p.32) defende a importância de se definir dois grandes eixos da formação docente da EPT, como: o primeiro relacionado à área de conhecimento específica, via graduação e pós-graduação, principalmente stricto sensu; o segundo refere-se à formação didático-políticopedagógica e às especificidades das áreas de formação profissional. Neste último, é fundamental que se

aproxime da problemática das relações entre educação e trabalho e do vasto campo da educação profissional e, em particular, da área do curso no qual ele está lecionando ou vai lecionar no sentido de estabelecer as conexões entre essas disciplinas e a formação profissional específica, contribuindo para a diminuição da fragmentação do currículo. (MOURA, 2008, p. 33).

O autor apresenta duas possibilidades concretas de formação de professores: cursos de licenciaturas para a educação profissional e, preferencialmente, pós-graduação lato e stricto sensu, diferenciadas de cursos de especialização, com carga horária superior a 360 horas, estágios de prática docente e de observação e/ou prática no mundo do trabalho na área profissional em que o docente atua ou atuará após concluir a respectiva formação. No entanto, faz grande ressalvas a licenciatura para a EPT, como: proximidade, contato e informação dos ingressantes sobre a profissão docente da EPT e a grande diversidade de áreas, cursos e disciplinas profissionais.

Observa o autor ainda, que essa formação, além das questões didático-políticopedagógicas, precisa enfocar a discussão relativa à função social da EPT em geral e de cada 
instituição em particular e a função docente indissociável do ensino-pesquisa em interação com os arranjos produtivos locais.

Diante deste cenário de várias propostas e possibilidades de formatação e execução de formação pedagógica para a EPT, a Resolução CNE/CEB no6/2012, define as Diretrizes Curriculares Nacionais para a Educação Profissional Técnica de Nível Médio e, no título IV, art. 40, trata da Formação Docente.

$\S 1$ ㅇ Os sistemas de ensino devem viabilizar a formação a que se refere o caput deste artigo, podendo ser organizada em cooperação com o Ministério da Educação e instituições de Educação Superior.

$\S 2$ - Aos professores graduados, não licenciados, em efetivo exercício na profissão docente ou aprovados em concurso público, é assegurado o direito de participar ou ter reconhecidos seus saberes profissionais em processos destinados à formação pedagógica ou à certificação da experiência docente, podendo ser considerado equivalente às licenciaturas:

I - excepcionalmente, na forma de pós-graduação lato sensu, de caráter pedagógico, sendo o trabalho de conclusão de curso, preferencialmente, projeto de intervenção relativo à prática docente;

II - excepcionalmente, na forma de reconhecimento total ou parcial dos saberes profissionais de docentes, com mais de 10 (dez) anos de efetivo exercício como professores da Educação Profissional, no âmbito da Rede CERTIFIC;

$[\ldots]$

$\S 4$ ㅇ A formação inicial não esgota as possibilidades de qualificação profissional e desenvolvimento dos professores da Educação Profissional Técnica de Nível Médio, cabendo aos sistemas e às instituições de ensino a organização e viabilização de ações destinadas à formação continuada de professores. (BRASIL, 2012, p. 12) (grifo nosso).

Apesar de recente, e de ter o caráter regulador, a Resolução CNE/CEB no 06/2012 ainda oportuniza até 2020 várias possibilidades para a formação pedagógica para a EPT, contudo, ressalta a forma de pós-graduação lato sensu, objeto deste estudo. Vale observar a preocupação com o reconhecimento dos saberes profissionais, via Rede CERTIFIC, o que desobriga tal formação. No entanto, reforça formação continuada como qualificação e desenvolvimento profissional.

Com isso corrobora Araujo (2008, p. 54)

O desafio visto, sob esta perspectiva, é não só capacitar, como insistem algumas políticas e/ou executores, mas promover uma cultura de valorização do professor que se traduza no reconhecimento efetivo da qualificação profissional docente como processo sem fim. (grifo nosso)

Processo esse que implica no desenvolvimento e/ou na construção do saber docente e compreende os saberes como: social, psicológico, legal, específico, pedagógico, tecnológico, a que se pretende a formação pedagógica para docentes da EPT.

O que é corroborado pela meta 15, do Plano Nacional de Educação (PNE) 2014-2024, e mais especificamente na estratégia 15.13 “desenvolver modelos de formação docente para a educação 
profissional[...]por meio da oferta, [...], de cursos voltados à complementação e certificação didático-pedagógica de experientes".(BRASIL, 2014, p.16-17)

Diante deste recorte da historiografia da Educação Profissional, observa-se que pouco se abordou sobre a formação pedagógica de professores para atuação em tal modalidade de ensino.

Corrobora e desabafa Machado sobre a improvisação na educação profissional, é

preciso e urgente definir uma política nacional ampla de valorização da formação dos professores para essa área e que isso passa pela superação de fato da tendência histórica às improvisações, pela institucionalização dessa formação, superação de preconceitos e real tratamento de equivalência formativa comparativamente à recebida pelos demais professores. De fato, há especificidades que precisam ser consideradas, mas por que continuar com o adjetivo especial? Se há necessidade de contar com vias diferentes de formação docente para a educação profissional, é preciso denominá-las pelo que eles têm de objetivo e alvo. Outra coisa é essa questão de dar prazos para acatar definições legais. A experiência histórica, nesse caso, mostrou que isso só serviu para protelar as decisões e ações. (MACHADO in INEP, 2008, p. 82) (grifo nosso)

Conclui-se que a legislação e políticas públicas refletem a preocupação com a formação, certificada, em serviço dos que atuam na Educação Profissional, Científica e Tecnológica e possibilitam as mais variadas formas e modalidades para a sua efetivação e estruturação, ressaltando, preferencialmente, a formação continuada e permanente como espaço de reflexão da prática docente associada à pesquisa e tecnologia.

Moura (2008, p. 10) afirma que

a formação e a capacitação devem, portanto, ir além da aquisição de técnicas didáticas de transmissão de conteúdos para os professores e de técnicas de gestão para os dirigentes [...] numa perspectiva de superação do modelo de desenvolvimento socioeconômico vigente, de modo que se deve priorizar mais o ser humano do que, simplesmente, as relações de mercado e o fortalecimento da economia.

Neste sentido, é imprescindível discutir na formação pedagógica dos docentes da EPT a sua função social; o papel, diferenciado, reflexivo e crítico, do docente e a indissociabilidade do ensino, da pesquisa, da tecnologia e do contexto socioeconômico.

A construção do saber e da prática docente se fundamenta nas teorias da educação, porém, com vista às necessidades de seu dia-a-dia e na análise crítica das políticas educacionais. Esta relação teoria e prática docente é bastante complexa, uma vez que envolve crenças, valores, histórias e relações socioeconômicas.

A sala de aula é o cenário das relações entre os conhecimentos científicos e o cotidiano e, consequentemente, para a efetivação do saber docente, que se dá com ações concretas fundamentadas nas teorias da educação e na relação ensino e aprendizagem com o estudante.

Nesse sentido, Machado complementa a identificação do docente da EPT 
é pressuposto básico que o docente da educação profissional seja, essencialmente, um sujeito de reflexão e da pesquisa, aberto aos trabalhos à ação crítica e cooperativa, comprometido com sua atualização permanente na área de formação específica e pedagógica. (MACHADO, 2008, p. 17).

\section{RESULTADOS E DISCUSSÕES}

\subsection{Desenvolvimento docente}

Os sujeitos da pesquisa são quatro professores não licenciados, cursistas e concluintes do Curso de Especialização em Docência para a EPT do IFMS-Coxim, identificados por PC.Com base nos relatos dos professores, tanto no memorial como nas entrevistas, quando perguntados acerca da constituição da docência, pode-se afirmar que essa se iniciou por diversas formas, com as mais variadas histórias e, em quase sua totalidade, sem intenção e nem planejamento, de forma inesperada.

[...] Então, 99/2000, como professor. E dai tava (sic) fora de Coxim, fiquei sabendo do IF e fiz o concurso tanto para docente quanto para analista, passei nos dois e minha intenção era ficar como analista, né?! Não queria docência, mas acabei sendo chamado primeiro para docente, daí ... gostei muito de dar aula no IF. (PC1) (grifo nosso)

O desinteresse e o acaso na escolha profissional podem ser observados na fala do professor PC2 "Então, acho que antes de ser professor eu pensei em ser funcionário público..." .

O professor PC3, quando questionado se possuía experiência docente antes da atuação no IFMS-Cx, responde: "Já, um pouquinho assim, mas não remunerado, né?! Algumas práticas do meu orientador...". (PC3)

Já o professor PC4, relata que recém-formado atuou como professor contratado na própria Universidade na qual se formou e que suas primeiras experiências como docente foram: "Péssimas! Eu queria desistir todas as aulas, a cada nova aula eu queria sair, não queria mais aquilo... de uma certa certeza que eu tinha era que, eu não queria ser professor...". (PC4 )

Desse grupo de quatro professores, três deles são originários da cidade de Coxim o que nos leva a identificar que a docência, mesmo não sendo o foco profissional inicial, foi efetivada por se tratar de uma oportunidade ímpar de profissionalização como servidor público federal e no lócus familiar e social.

Então, eu fiquei muito interessado em entrar para o Instituto, depois fiquei sabendo que vinha para Coxim um campus do Instituto, eu falei... e tava (sic) em Campo Grande querendo voltar... ai eu falei, acho que dá pra ser também. (PC2) (grifo nosso)

Considerando que os professores se graduaram em bacharel na primeira década dos anos 2000, porém três deles tiveram pouca experiência profissional, outro nenhuma, e mesmo sem formação específica, pedagógica, ainda assim se dispuseram e se dedicaram à construção da docência, buscando caminhos para ensinar, o que os levou ao encantamento com a profissão, 
conforme declaração do PC4 "... eu sofri muito no começo, mas depois eu acabei, meio que, tomando gosto pela coisa".

Segundo Burnier (2007, p.348), "o indivíduo constrói sua identidade profissional criando representações sobre si mesmo e suas funções, interligadas à sua história de vida, formação e profissionalização", que confirma Araujo $(2008$, p.60) "não podemos desprezar as experiências acumuladas em diferentes ações e processos de formação de professores para atuar em educação profissional".

\subsection{Experiência docente}

Neste tópico são apresentadas as primeiras impressões dos sujeitos sobre a docência. Assim, os professores PC1 e PC2 afirmam que enfrentaram dificuldades nas primeiras experiências docentes, seguem relatos.

Ah! Foi legal?! Mas ... Fiquei um pouquinho nervoso, tal ... Sou muito tímido, mas pra dar aula não to nem ai (sic) ... (PC1)

É, eu tive uma experiência anterior no curso superior de sistemas de informação que foi um pouco tranquila ... é, bem mais tranquila que minha estreia no IF para o ensino médio, (...), aqui com receio das crianças, né?! Dos mais jovens, da faixa etária. Fiquei um pouco mais apreensivo. Eu oscilei ... na primeira e segunda semana... na primeira, gostando muito, e segunda semana, querendo mandar um currículo para outro lugar ... pra me livrar daquele constrangimento que eu sentia durante as aulas em algum momento ... porque eu não tinha controle da sala ..., porque, às vezes, até a questão da organização do tempo, de não saber aproveitar o tempo da sala mesmo, de não preparar exercícios suficientes, por exemplo, e ficar com um mal estar, né?! (PC2)

Nos relatos dos sujeitos percebe-se de forma explícita que as dificuldades em preparar as aulas se deram por falta de experiência em docência e de forma implícita por ausência de formação pedagógica.

O PC4 traz em seu apontamento ainda a defasagem na formação inicial.

Péssimas!! Eu queria desistir todas as aulas, a cada nova aula eu queria sair, não queria mais aquilo... eu me sentia sabendo menos que os alunos em alguns casos... que mais... até porque eu sai recém-graduado, fui dar aula é...de conteúdos que eu tinha defasagem na minha graduação... então, me sentia muito inseguro! (PC4)

Conforme afirma Moura, é inteiramente compreensível todas essas inquietações e dificuldades dos professores não licenciados, considerando que em suas formações iniciais não contemplavam preparação para o exercício da docência, isso é formação pedagógica.

No caso do docente advindo dos cursos de bacharelado, tanto os que se dedicam exclusivamente à docência quanto aqueles que acumulam a atividade técnica e o magistério, a ausência formativa é um grande desafio, uma vez que sua formação inicial não possui, na grade curricular, na maioria dos casos, disciplinas para a 
formação de professores, conhecimentos técnicos que o habilite para o magistério superior. (MOURA, 2009, p. 4).

\subsection{Construção dos saberes docentes}

Consideramos neste tópico, as fontes inspiradoras para as práticas docentes e a construção dos saberes dos professores não licenciados, com referência nos depoimentos dos sujeitos. Para tanto, foram indagados acerca das fontes inspiradoras de suas práticas docentes.

É nítido que o processo de constituição dos saberes docentes sofre significativa influência das vivências acadêmicas e práticas dos docentes entrevistados, de acordo com os apontamentos:

É lógico, a referência são seus professores antigos mesmo. [...] Mas a minha maior referência é isso, são os professores que eu tive! (PC1)

(...) a gente, às vezes, se espelha num professor que já teve ou professor que teve e não ser daquele jeito [...] risos [...] ou olhar e falar "Ah, essa prática é boa e acho q eu vou adotar?!" (PC3)

Nunes (2001, p. 34) descreve a concepção de Gauthier sobre o saber do professor que "pode ser racional sem ser um saber científico, pode ser um saber prático que está ligado à ação que o professor produz, um saber que não é da ciência, mas que não deixa de ser legítimo" e que o profissional, munido desses saberes, "deve deliberar, julgar e decidir com relação à ação a ser adotada, ao gesto a ser feito ou à palavra a ser pronunciada antes, durante e após o ato pedagógico".

O professor PC4 traz ainda outro elemento, a preocupação em ser bom professor e fonte inspiradora para os seus estudantes.

É... eu acho assim... o que me inspirou de certa forma, acho que sempre são os professores, por isso até que eu acho que eu tento ser um bom professor, porque a gente que serve de exemplo, né?! (sic) (PC4 - Entrevista)

Ratifica Nunes (ibidem) sobre modelo de professor,

deve-se levar em conta o contexto no qual se constroem e se aplicam os saberes docentes, isto é, as condições históricas e sociais nas quais se exerce a profissão; condições que servem de base para a prática docente. Este professor possui, em virtude da sua experiência de vida pessoal, saberes próprios que são influenciados por questões culturais e pessoais.

Já o professor PC3 se utiliza de "livros, referências ou ... várias coisas ... ou mesmo pessoas influentes na área ou não ... tentando buscar em livros, artigos ou referências ou com colegas, também, com trocas de ideias e informações..." como fontes de inspiração para a constituição de saberes. A afirmação do sujeito indica que o docente utiliza-se de busca pessoal por formação, porém acredita no compartilhamento de experiências com os afins.

Perrenoud (2001, p.16) traz a seguinte afirmação seguida de questionamentos "Ninguém duvida de que, para ensinar, é preciso dominar os saberes a ensinar. Até que ponto? [ ...] Para ensinar, deve-se dominar outros saberes além daqueles que serão ensinados?" 
Quando questionados sobre suas percepções sobre a preparação para serem professores, respondem:

Eeh! Acho que de conteúdo a gente nunca tá preparado, porque a gente tá sempre estudando,... E, também, de metodologia de ensino, também, a gente tá sempre descobrindo coisas novas." (sic) (PC 1)

“Preparado?! Olha... é uma pergunta... interessante!... Talvez assim, eu que acho que com relação à metodologia e ao conteúdo que eu tenho a oferecer, eu acho que eu tenho uma boa preparação. Não a que eu gostaria ... (sic) (PC 2)

Observa-se nos apontamentos anteriores que para os sujeitos a constituição dos saberes abrange tanto os saberes experienciais, quanto os disciplinares, curriculares e pedagógicos, que representam o saber docente. Conforme afirma Tardif (2006, p.36) "Pode-se definir o saber docente como um saber plural, formado pelo amálgama, mais ou menos coerente, de saberes oriundos da formação profissional (pedagógicos) e de saberes disciplinares, curriculares e experienciais." (complementação nossa) E, complementa o autor (ibidem, p.39), "os saberes são elementos constitutivos da prática docente".

Em suma, o professor ideal é alguém que deve conhecer sua matéria, sua disciplina e seu programa, além de possuir certos conhecimentos relativos às ciências da educação e à pedagogia e desenvolver um saber prático baseado em sua experiência cotidiana com os alunos.

Essas múltiplas articulações entre a prática docente e os saberes fazem dos professores um grupo social e profissional cuja existência depende, em grande parte, de sua capacidade de dominar, integrar e mobilizar tais saberes enquanto condições para a sua prática. (TARDIF, 2006, p. 39).

Nunes corrobora com Tardif quando afirma que

o saber é considerado como resultado de uma produção social, sujeito a revisões e reavaliações, fruto de um interação entre sujeitos, fruto de uma interação lingüística inserida num contexto e que terá valor na medida em que permite manter aberto o processo de questionamento. (sic) (NUNES, 2011, p.34)

\subsection{Formação docente}

Iniciamos esse tópico com o relato do professor PC1 que nos traz que além do conteúdo o professor precisa se ater à afetividade nas relações, indicada como postura.

Ele precisa do conteúdo, mas eu acho que o que é mais importante é a postura, eu acho, né?!... Essa postura de saber respeitar que o outro não sabe do nível dele, de ser cordial com o aluno, ser prestativo ali, eu acho que falta em muitos professores... Acho que a postura ainda é mais importante que as metodologias, porque a metodologia pode não ser a melhor, mas se a postura bem... de uma pessoa bem intencionada, o aluno até se esforça para ir lá e tirar dúvida com o professor. (PC1 - Entrevista) (grifo nosso) 
A esse apontamento contribuem Tardif e Lessard (2013, p.44) com afirmação que "o trabalho docente não se limita nem às atividades de classe, nem às relações com os alunos, embora essas atividades e relações [...] sejam essenciais no exercício da profissão."

Utilizou-se o conceito de formação docente de Imbernón, no caso desse estudo, do saber pedagógico.

O conhecimento profissional consolidado mediante a formação permanente apoia-se tanto na aquisição de conhecimentos teóricos e de competências e rotinas como no desenvolvimento de capacidades de processamento da informação, análise e reflexão crítica em, sobre e durante a ação, o diagnóstico, a decisão racional, a avaliação dos processos e a reformulação de projetos." (IMBERNÓN, 2011, p. 75).

O mesmo autor quanto à formação pedagógica traz que

a formação do professor deve estar ligada a tarefas de desenvolvimento curricular, planejamento de programas e, em geral, melhoria da instituição educativa, e nelas implicar-se, tratamento de resolver situações problemáticas gerais ou específicas relacionadas ao ensino em seu contexto. (idibem, p. 18).

Moura ratifica a necessidade da formação pedagógica para os professores bacharéis quando diz que

um docente que não teve, em sua formação inicial, preparo para a docência precisa adquirir mecanismos, instrumentos, para a construção de um aparato que Ihe permita realizar o seu trabalho em sala-de-aula. (MOURA, 2009, p. 1).

Complementa a isso, o domínio do conteúdo do qual está ministrando, além de técnicas de transmissão e organização do mesmo a fim de torná-lo compreensível e assimilável ao estudante.

A afirmação do PC2 identifica a importância de formação permanente ao longo da vida profissional e que essa faça parte da atividade docente.

Então, tecnicamente falando, eu me sinto preparado, tecnicamente, conteúdo específico para ministrar para os alunos. Agora, pedagogicamente, eu acho que eu tenho muito a melhorar, acho que todos os professores têm muito a melhorar, que é tentar criar novos métodos de aprendizagem, outras abordagens para o aprendizado, outras formas de avaliação que não distancie tanto dos alunos que têm dificuldade, acho isso, pedagogicamente eu tenho muito... acho que não to preparado, assim como eu não conheço nenhum exemplar desse que esteja pedagogicamente preparado para todas as situações... (PC2) (grifo nosso)

Segundo Imbernón (idibem, p. 47) "os dilemas, as dúvidas, a falta de estabilidade e a divergência também constituem o desenvolvimento profissional" e complementa, "a formação será legítima então quando contribuir para o desenvolvimento profissional do professor no âmbito do trabalho e de melhoria das aprendizagens profissionais".

Contribuem Tardif e Raymon que a construção dos saberes se dá ao longo da carreira docente remetendo a ideia de domínio progressivo dos saberes docentes, que incluem os aspectos 
didáticos e pedagógicos, a organização escolar e as relações interpessoais, o que contribui para a construção da identidade profissional.

É apenas ao cabo de um certo tempo - tempo da vida profissional, tempo da carreira - que o eu pessoal, em contato com o universo do trabalho, vai pouco a pouco se transformando e torna-se um eu profissional. A própria noção de experiência, que está no cerne do eu profissional dos professores e de sua representação do saber ensinar, remete ao tempo, concebido como um processo de aquisição de um certo domínio do trabalho e de um certo conhecimento de si mesmo. (TARDIF e RAYMOND, 2000, p. 239)

Todavia, quando questionados sobre a importância da formação pedagógica para sua prática docente, os sujeitos consideram

que ajuda bastante, acho que ajuda sim. É... você conhecer novas formas de ensinar ajuda, mas, o jeito que é passado isso, às vezes, a gente fica meio..., não vê sentido ou fica perdido em tantas teorias, talvez pra nós, principalmente, eu acho que é mais prático, a gente é mais prático da área de exatas, queria algo "oh! pra sua área isso aqui funcionou legal, essa prática pra esse conteúdo funcionou legal", entendeu?! [...] fica muito aberto... muito na teorização e a gente do curso técnico sempre fala: os técnicos, eles têm que saber mais prática do que teorização, do que ciência, científico, né?! E a gente cobra isso deles, é prática o tempo todo, e as metodologias de ensino do jeito que são passadas para nós ficam sempre na teorização! (risos). (PC1) (grifo nosso)

A afirmação desse professor indica que valoriza a formação pedagógica, porém com postura reflexiva insipiente que subsidie a prática docente. $O$ que vai de encontro com a afirmação do professor PC2, que indica que a formação pedagógica possibilita melhor exercício da docência vinculada à formação humana.

Olha... eu acho que o saber pedagógico, por mais que todos tentem enjaular eles em certas regras e certas métricas e soluções, eu acho que ele não passa por isso. A gente vê quem estuda, gente que tem licenciatura, que a gente vê que poderia ter um articulação mais apropriada para determinada situação, isso não acontece! (PC2) (grifo nosso)

Entretanto o professor PC3 indica um despertar à reflexão na ação docente quando admite que

você não sabia que era o... Paulo Freire, depois você fala, olha! Eu já estava aplicando isso e não sabia [...] Agora é juntar o que eu estava fazendo com a teoria que é praticada. Não tinha esse link. Tinha coisa que era lá... e você já fazia, e esse teórico que aplica isso... E isso soma, né?! (PC3) (grifo nosso)

O professor PC4 concorda que além dos conhecimentos específicos utiliza-se de outros saberes em sua prática, no entanto ainda de forma reticente à teoria pedagógica. "Sim, com certeza! Eu acho que ... (risos)... não necessariamente, tem que estar pautado nos teóricos da educação ou do ensino,..."

E complementa 
[...] eu acho que o conhecimento específico não é tudo mas, também o conhecimento teórico da educação não resolve todos os problemas, se não já teria resolvido! Acho que cabe a você pegar o que tem de bom de cada um e usar como ferramenta, né?! Minha opinião é essa! Saberes pedagógicos. (PC4) (grifo nosso)

Tardif (2006, p.274) justifica que "para os professores, [...] nem sempre é fácil teorizar a sua prática e formalizar seus saberes, que eles veem como sendo pessoais, tácitos e íntimos".

Os relatos dos professores indicam resistência no aceite das contribuições dos fundamentos pedagógicos para a prática docente, que é corroborado por Araújo.

Muitos professores não se reconhecem como docentes, mas como técnicos (engenheiros, biólogos químicos, etc.). Isso evidencia uma resistência muito forte aos apelos por uma ação fundada nas contribuições da pedagogia. ARAUJO (2008, p. 61) (grifo nosso)

E ainda, a formação para a EPT por meio do Curso de Especialização do IFMS-Cx é vista apenas para "cumprir uma obrigatoriedade prevista na LDB e também por suprir a grade curricular referente à licenciatura e à educação profissional tecnológica, uma vez que sou bacharel e não licenciado", conforme apontamento do sujeito PC4, em memorial descritivo.

Desta forma, não queremos aqui, apontar a supremacia dos saberes pedagógicos aos saberes específicos, conforme apostados nos relatos com certa irritação, mas observar que com o conhecimento da pedagogia é possível organizar, fundamentar, revisar e até combater certas práticas docentes.

No entanto, os professores cursistas quando indagados a respeito da importância e da interferência dos saberes pedagógicos em suas práticas docentes, ratificaram a contribuição, porém de forma insipiente e vacilante.

Sobre a interferência dos saberes pedagógicos, o professor PC3 sinaliza "acho que não (interfere)... acho que contribui! Acho que soma, seja na parte técnica ou não ... acho que tudo tem que ser somado. $\mathrm{Ai}$, a gente sempre pega as partes que são boas pra contribuir...". O professor PE4 observa que os saberes pedagógicos podem ajudar à prática docente, porém eles "não define um bom ou mau professor".

No entanto, o mesmo professor PC4 no memorial descritivo aponta que a busca pela qualificação, como a oferecida pelo IFMS-Cx por meio do Curso de Especialização é necessária para a melhoria de sua prática que se faz reflexiva para "aprimorar a maneira de trabalhar as disciplinas e envolver os alunos".

Imbernón corrobora com os relatos dos professores a respeito da construção de saberes e, ainda, enfatiza a importância do ambiente educativo para a consolidação dos conhecimentos. Uma vez que a cada vivência profissional, o docente se vê obrigado a elaborar e construir o sentido para a prática docente.

a consolidação do conhecimento profissional educativo mediante a prática apoiase na análise, na reflexão e na intervenção sobre situações de ensino e aprendizagem concretas, e, é claro, em um contexto educativo determinado e 
específico [...] que o conhecimento experimentado por meio da prática, ou seja, o trabalho, intervindo nos diversos quadros educativos e sociais, instituições educativas e comunidade, em que se produz a docência. IMBERNÓN (2011, p. 9).

Nesse sentido, Tardif e Lessard (2013, p.43) contribuem que "a docência também comporta diversas ambiguidades, diversos elementos "informais", indeterminados, incertezas, imprevistos" e essas variáveis permitem ao docente usufruir de sua autonomia e conhecimentos "tanto para interpretar como para realizar sua tarefa, principalmente quanto às atividades de aprendizagem em classe e à utilização de técnicas pedagógicas." E complementam, ainda, que

ensinar, de certa maneira, é sempre fazer algo diferente daquilo que estava previsto [...]. Enfim, é agir dentro de um ambiente complexo e, por isso, impossível de controlar inteiramente [...] na medida em que a interação [...] com os alunos é portadora de acontecimentos e intenções que surgem da atividade. TARDIF e LESSARD (ibidem)

E para finalizar os mesmos autores sintetizam o trabalho docente e os saberes que o fundamentam considerando as tendências das pesquisas sobre o assunto, de Schön, Perrenoud e demais autoridades.

A docência começa a ser apresentada como um trabalho fortemente contextualizado, concreto, posicionado (SCHÖN, 1983), marcado principalmente pelas contingências situacionais. Ensinar torna-se uma atividade de improvisação mais ou menos regulada, (PERRENOUD, 1996; TOCHON, 1993) de certa maneira parecida com o free jazz e fundamentada na intuição (ELBAZ, 1983). A docência é, então, concebida como um "artesanato", uma arte aprendida no tato, realizada principalmente às apalpadelas e por reações parcialmente refletidas em contextos de urgência. Os fundamentos cognitivos desse trabalho, ou seja, o conjunto de conhecimentos, competências e habilidades necessárias ao seu cumprimento diário, assumem aqui uma coloração bastante experimental, existencial: o "saber ensinar" parece um recurso exclusivo da vivência, da experiência pessoal, até a história anterior, familiar ou escolar (BUTT et., 1988; CARTER \& DOYLE, 1996). Afetividade também assume, aqui um lugar de destaque, pois é a partir das experiências afetivas fortes (relações com os alunos, experiências difíceis ou positivas, etc.) que o "eu-profissional" do professor (ABRAHAM, 1984) se constrói e se atualiza. (ibidem, p. 46).

Assim, a intenção neste tópico foi observar nos relatos dos sujeitos se o Curso de Especialização despertou a atitude reflexiva em relação à prática docente porque essa permite "outras possibilidades de ação e de formação", e ainda, que privilegie tanto "os aspectos técnicos para o mundo do trabalho", como o humanístico, "integral incorporando ciência, trabalho, tecnologia e cultura como eixos indissociáveis", como explicitado por Oliveira \& Silva $(2012$, p.195)

\section{CONSIDERAÇÕES FINAIS}

Por meio das análises, apresento alguns resultados, considerações e reflexões sobre a formação docente da EPT, por meio do curso de Especialização em Docência para EPT. 
Os dados nos mostram que a constituição da docência dos professores entrevistados se deu de forma bem variada e inesperada, o que é justificado pela formação inicial em bacharelado. $E$ teve como motivação a oportunidade profissional no lócus familiar e social de origem. No entanto, há a identificação desses bacharéis com a docência.

Observa-se, também, ser plausível o ingresso frequente de bacharéis e tecnólogos na docência, considerando a inexistência de licenciaturas que atenda a todos os eixos tecnológicos propostos pelos Institutos Federais e cabendo a esses a formação em serviço dos docentes.

Mas o que é docência e qual o papel do professor? Segundo os cursistas a docência é a transmissão de conteúdo e para isso o professor é orientador, motivador e mediador da aprendizagem que necessita de constante qualificação e atualização, o que sugere, de certa forma, o compromisso com o saber pedagógico.

Na percepção dos professores, referenciadas nos relatos, as primeiras experiências foram desafiadoras pela ausência de formação pedagógica, tanto na lida com o estudante, quanto no domínio pedagógico e na adequação de conteúdos ao ensino profissional. Assim, reconhecem a necessidade dessa formação para o exercício da docência e, ainda, da preparação para a profissão, que se dá por meio de integração com os demais colegas, por influência das experiências acadêmicas, pessoais e práticas vivenciadas, e por meio de estudos. Pode-se deduzir que esse reconhecimento à importância da formação pedagógica se deu com a vivência profissional e acadêmica, proposta pelo Curso de Especialização, o que oportunizou a visão crítica do saber docente e, por sua vez, do pedagógico.

Os sujeitos da pesquisa destacaram, também, a importância da formação pedagógica. Porém alguns apresentam resistência no aceite das contribuições dos fundamentos pedagógicos para a prática docente, mas, ao mesmo tempo, mostram-se preocupados com a formação integral do estudante, quando se interessa por sua realidade e com sua aprendizagem, por meio de aplicação de novas metodologias e adequação de conteúdos.

Pode-se constatar nos relatos, ainda, ênfase no saber experiencial para a docência, que por sua vez contribui com a construção do saber pedagógico, já que os valores, crenças e saberes desenvolvidos a partir de sua história de vida são agregados e aplicados na docência, servindo de reflexão e construção da própria prática, quando apontam que reproduzem práticas pedagógicas positivas de seus antigos docentes.

Assim, entende-se que a docência se dê num tripé no qual se relacionam as questões pessoais, profissionais e organizacionais e permeando essas relações encontram-se os saberes necessários a ensinar, não exclusivamente pedagógicos, mas saberes docentes que compreendem conhecimentos da área pedagógica, de didática, de relacionamento interpessoal professor-aluno e aluno-aluno, de formação integral do estudante e de gestão.

Durante esse estudo pode-se observar que os saberes são construídos, reconstruídos e socializados entre os colegas de acordo com as vivências docentes e que remetem à construção de novos saberes.

É possível considerar que o curso de Especialização para Docência em EPT apresentou limites e possiblidades. Por um lado, dentre os limites identifica-se em alguns relatos que a preocupação com formação pedagógica não prepondera sobre a do conteúdo específico. De outro 
lado, as possibilidades apontam para a contribuição teórico-metodológica na comunidade, de modo a efetivar os arranjos produtivos locais. Evidenciando o que os relatos apontam que o trabalho docente exige constante e permanente qualificação e atualização. Neste sentido, houve contribuição do curso para a construção do saber docente tanto dos docentes não licenciados.

Desse modo, este estudo possibilitou a reflexão sobre a necessidade e importância de formação docente diferenciada e permanente, em ambiente mediador e coletivo de saberes para ensinar na Educação Profissional Científica e Tecnológica.

\footnotetext{
"Não preciso esperar saber tudo para agir. Ninguém nunca sabe tudo e é a própria ação que permite progredir no saber." (LEBRET in LüCK, 2014).
}

\section{REFERÊNCIAS}

AGUIAR, O.R.B.P; FERREIRA, M.S. Ciclo de estudos reflexivos: uma estratégia de desenvolvimento profissional docente. Pesquisa em Educação: Múltiplos Olhares. Brasília: Liber Livro Editora, 2007. ARAUJO, R.M.L. Formação de docentes para a educação profissional e tecnológica: por uma pedagogia integradora da educação profissional. Trabalho \& Educação, Belo Horizonte, v.17, p 5363, mai/ago.2008.

BRASIL. Resolução CNE/CEB no6 de 20 de setembro de 2012.

DIAS, D. S. D e ARANHA, A. V. S. Trabalho docente: desafios à produção de saberes no contexto da inclusão social escolar. Educação e Tecnologia. Belo Horizonte. v.12, n.3, p.46-49, set/dez, 2007.

DORIGON, T.C. e ROMANOWSKI, J.P. A reflexão em Dewey e Schön. Revista Intersaberes, Curitiba, ano 3, n.5, p. 8-22, jan/jul 2008.

GARIGLIO, J.A e BURNIER, S. Saberes da Docência na Educação Profissional e Tecnológica: um estudo sobre o olhar dos professores. Educação em Revista. Belo Horizonte. v.28, n 01, p. 211236, $\mathrm{mar} / 2013$.

GOMES, H. M. Formando Professores para a Educação Profissional. 2004. Disponível em: http://27reuniao.anped.org.br/gt08/t086.pdf

IMBERNÓN, F. Formação Docente e Profissional: formar-se para a mudança e a incerteza. 9. ed. São Paulo: Cortez, 2011.

KRAHE, E. D, et al. Políticas Curriculares para a Formação de Professores: a ampliação da docência e a redução do tempo. IX ANPED Sul. 2012. p.1-15.

LEITE, Y. U. F ; GHEDIN, E.; ALMEIDA, M.I. Formação de professores: caminhos e descaminhos da prática. Brasília, DF: Liber Livro Editora, 2008.

LÜDKE, M. e BOING, L.A. O trabalho docente nas páginas de Educação e Sociedade em seus (quase) 100 números. Educação\&Sociedade, v.28, n.100, out/2007.

MACHADO, L. R. S. Diferenciais Inovadores na Formação de Professores para a Educação Profissional. Revista Brasileira da educação Profissional e Tecnológica. v.1. 2008. p. 8-22.

. Formação de Professores para Educação Profissional e Tecnológica. Brasília: Instituto Nacional de Estudos e Pesquisas Educacionais Anísio Teixeira, 2008. pp.67-82. - (Coleção Educação Superior em Debate; v. 8)

MOURA, D.H. A formação de docentes para educação profissional e tecnológica. Revista Brasileira da Educação Profissional e Tecnológica, Brasília, 2008.

NÓVOA, A. Formação de Professores e Profissão Docente. Aveiro, Portugal, 1991. Disponível em: http://hdl.handle.net/10451/4758 
NUNES, C.M.F. Saberes Docentes e Formação de Professores: um breve panorama da pesquisa brasileira. Educação \& Sociedade, ano XXII, no74,abril/2001.

PASSOS, S.R.M.M.S; NOVICKI,V. Formação de Professores para a Educação Profissional: desafios atuais. Eixo 4: Política e Gestão da Educação Profissional e Tecnológica. 2013. Disponível em: http://www.anpae.org.br/simposio26/1comunicacoes/SaraRozindaMartinsMoura-ComunicacaoOral-int.pdf PEREIRA, L.A.C. A formação de professores e a capacitação de trabalhadores da educação profissional e tecnológica. In: Fórum de Educação Profissional (Anais), 2004.

PIMENTA. S.G (Org.). Professor: formação, identidade e trabalho docente. In: Saberes Pedagógicos e Atividade Docente. 8. ed. São Paulo: Cortez, 2012. pp.13-38.

TARDIF, M.; LESSARD, C. 0 trabalho docente: elementos para uma teoria da docência como profissão de interações humanas. 8. ed. Petrópolis, RJ: Vozes, 2013.

TARDIF, M. Saberes docentes e formação profissional. 7. ed. Petrópolis, RJ: Vozes, 2006. 